\title{
O INDISSOCIÁVEL TRIPÉ ENSINO, PESQUISA E EXTENSÃO \\ NA FORMAÇÃO DO PROFISSIONAL JURISTA APTO \\ A ATUAR NAS DEMANDAS SOCIAIS
}

\section{THE INSEPARABLE TRIPOD TEACHING, RESEARCH AND EXTENSION IN THE TRAINING OF THE PROFESSIONAL JURIST ABLE TO ACT IN SOCIAL DEMANDS}

\section{RESUMO}

Se pensar numa educação para além da sala de aula - através do incentivo à pesquisa e à extensão - é de extrema relevância na formação profissional do estudante do curso de graduação em Direito. Através da pesquisa e da extensão, o futuro jurista convive com a realidade de sua comunidade e prepara-se para, futuramente, atuar nela. Nesse sentido, o presente estudo tem como objetivo analisar a importância da associação do ensino, da pesquisa e da extensão nos cursos de graduação em Direito, bem como no processo de formação de profissionais juristas competentes, éticos e capazes de atuar nas demandas sociais. Para tanto, tratou-se, primeiramente, de compreender os conceitos de pesquisa e extensão quando associadas ao ensino universitário. Logo após, buscou-se examinar quais os mecanismos que as universidades devem utilizar na formação dos profissionais juristas, por meio da análise da legislação que rege os cursos superiores de graduação em Direito no país.

Palavras-chave: Cursos de graduação em Direito. Tripé universitário. Ensino. Pesquisa. Extensão.

\section{ABSTRACT}

To think about education beyond the classroom - by encouraging research and extension - is of extreme relevance in the professional training of the law student. Through research and extension, the future jurist gets in touch with the reality of their community and prepares to work in it in the future. In this sense, the present paper aims to analyze the importance of the association of teaching, research and extension in undergraduate courses of Law, as well as in the process of training competent, ethical and professional jurists, those capable of acting on social demands. To do so, it was firstly necessary to understand the concepts of research and extension when associated with university education. Afterwards, it was sought to examine what mechanisms universities should use in the training of legal professionals, through the analysis of the legislation that gives the foundation for the law courses in the country.

Keywords: Undergraduate courses of Law. University tripod. Teaching. Research. Extension.

\section{INTRODUÇÃO}

As universidades são instituições pluridisciplinares de ensino superior responsáveis pela 
preservação, produção e transmissão de conhecimentos culturais, científicos e tecnológicos, bem como pela formação intelectual, técnica, profissional e ética de seus estudantes.

No Brasil, o surgimento das universidades se deu, em geral, de forma tardia. Conforme elenca Wolkmer (2000, p. 67), as primeiras faculdades de Direito, como exemplo, só foram fundadas em 1827 (quais foram, a Faculdade de Direito de Olinda e a Faculdade de Direito de São Paulo). Com o passar dos anos, a educação de ensino superior no país foi se transformando, complexando-se. Em igual medida, a legislação acompanhou cada mudança. Com o passar dos anos, a educação de ensino superior no país foi se transformando, complexando-se. Em igual medida, a legislação acompanhou cada mudança.

Hoje, a educação de nível superior e, em especial, o incentivo ao ensino, à pesquisa e à extensão nos cursos de graduação em Direito, encontram-se regulamentados pela Constituição Federal de 1998 (CF/88), pela Lei n ${ }^{\circ} 9.394$ - a chamada Lei de Diretrizes e Bases da Educação Nacional (LDB) -, e pela Resolução n ${ }^{\circ} 5$ de 17 de dezembro de 2018, a qual trata dos nortes curriculares nacionais dos cursos de graduação em Direito.

É sabido que, para que os cursos de graduação em Direito cumpram sua função social - qual seja, corroborar para a formação ética e profissional dos estudantes -, faz-se necessário a utilização do indissociável tripé ensino, pesquisa e extensão, tendo em vista que o ensino, quando associado à pesquisa e à extensão, provê um suporte intrínseco para o desenvolvimento científico, tecnológico e cultural do país.

Na presente resenha, será analisada a importância de um ensino para além da sala de aula, isto é, um que dialogue com a sociedade através das atividades de pesquisa e extensão; bem como de que modo as universidades devem atuar para atender às perspectivas elencadas na legislação que rege os cursos superiores de graduação em Direito no país, qual seja a Lei 9.394/96 e a Resolução nº 5 de 2018.

\section{A IMPORTÂNCIA DA APLICABILIDADE DO INDISSOCIÁVEL TRIPÉ} UNIVERSITÁRIO NOS CURSOS DE GRADUAÇÃO EM DIREITO

É através do texto constitucional que emerge a ideia do indissociável tripé universitário, compreendido, neste estudo, como a dialogicidade do ensino, da pesquisa e da extensão. Assim, a partir de 1988, as instituições de ensino superior, incluindo os cursos de graduação em Direito, objeto de análise da resenha, deveriam trabalhar esses três eixos de forma equânime e imanente.

A Constituição da República Federativa do Brasil de 1988, no decorrer de seu artigo 206, estabelece que o ensino brasileiro será ministrado com base nos princípios da liberdade de aprender, de ensinar, de pesquisar e de divulgar o pensamento, a arte e o saber, bem como no pluralismo de ideias e de concepções pedagógicas, e na coexistência de instituições públicas e privadas de ensino. No mesmo sentido, ressalta que as universidades da nação "gozam de autonomia didático-científica, administrativa e de gestão financeira e patrimonial, e obedecerão ao princípio de indissociabilidade entre ensino, pesquisa e extensão" (art. 207, $\mathrm{CF} / 88)$. 
Além da CF/88, a Lei 9.394 de 1996 estabelece, em seu artigo 43, que a educação superior tem por finalidade, dentre outras, estimular a criação cultural e o desenvolvimento do espírito científico e do pensamento reflexivo; incentivar o trabalho de pesquisa e investigação científica, visando o desenvolvimento da ciência e da tecnologia e da criação e difusão da cultura; e promover a extensão, aberta à participação da população, visando à difusão das conquistas e benefícios resultantes da criação cultural e da pesquisa científica e tecnológica geradas na instituição.

É certo que o trabalho mútuo entre o ensino, a pesquisa e a extensão tem sido fundamental para formar profissionais juristas com habilidades em diferentes áreas de conhecimento e com uma visão mais crítica dos acontecimentos em sua volta. Estudantes engajados na graduação, que se dedicam não só às aulas, mas também a monitorias, palestras, grupos de estudo e pesquisa, atividades de campo (o que inclui visitas, entrevistas com profissionais formados, etc.), oficinas, minicursos, cursos extras e práticas jurídicas, isto é, aqueles discentes que aproveitam em sua totalidade o ofertado pela universidade, tendem a possuir um perfil profissional diferenciado e a se destacarem no mercado de trabalho.

Paulo Freire, um dos pensadores mais notáveis na história da educação, trazia em suas obras a ideia da autonomia do ser educando. Para efeitos atuais, pode-se compreender essa como a capacidade dos educandos de intervirem na sociedade, de pesquisar, de comparar, de decidir, de romper, de realizar ações e dignificantes testemunhos. Para o autor, a educação nada mais é que "uma forma de intervenção no mundo" (1996, p. 110). Portanto, trabalhar com os estudantes para além dos limites da sala de aula é trabalhar as possibilidades de uma formação mais crítica e alinhada às diversas realidades fora da universidade. Para Freire (1996, p. 77),

Somos os únicos seres que, social e historicamente, nos tornamos capazes de aprender. Por isso, somos os únicos em que aprender é uma aventura criadora, algo, por isso mesmo, muito mais rico que meramente repetir a lição dada. Aprender para nós é construir, reconstruir, constatar para mudar, o que não se faz sem abertura ao risco e à aventura do espírito.

O referido pensador contribuiu para a educação de forma significativa, expondo a ideia da indissociabilidade entre ensino e pesquisa, de modo que quem ensina carece de pesquisar e quem pesquisa carece de ensinar, pois sem pesquisa não há ensino. Para o autor (1996, p. 32),

\footnotetext{
Não há ensino sem pesquisa e pesquisa sem ensino. Esses que-fazeres se encontram um no corpo do outro. Enquanto ensino continuo buscando, reprocurando. Ensino porque busco, porque indaguei, porque indago e me indago. Pesquiso para constatar, constatando, intervenho, intervindo educo e me educo. Pesquiso para conhecer o que ainda não conheço e comunicar ou anunciar a novidade.
}

Assim, Freire mostra que não tem o que ensinar aquele que não pesquisa, e que, através da pesquisa, ensina-se e realiza-se a extensão. Em conformidade com o autor, o conhecimento se constitui nas 
relações homem-mundo e se aperfeiçoa na problematização crítica destas relações. Contudo, este conhecimento só é produzido por meio de uma dialogicidade na relação entre os participantes das atividades extensivas, ou seja, através da “comunicação" onde ambos se tornam sujeitos de transformação da sociedade (FREIRE, 1996, p. 32). De acordo com o educador (1982, p. 95),

A construção e a produção do conhecimento do objeto implicam no exercício da curiosidade, sua capacidade crítica de tomar distância do objeto, de observá-lo, de delimitá-lo, de cindi-lo, de carcar o objeto ou fazer sua aproximação metódica, sua capacidade de comparar, de perguntar.

Desse modo, pode-se dizer que a extensão universitária é um processo educativo, cultural e científico, que articula o ensino e a pesquisa de forma indissociável e viabiliza a relação transformadora entre a universidade e a sociedade. A extensão, pois, é um trabalho social cujo produto corrobora com a transformação da coletividade. Para Machado (2013, p. 2), a extensão universitária é um espaço mútuo de integração e conversa entre a universidade e a sociedade, de modo que os saberes da comunidade devem ser valorizados e integrados aos conhecimentos científicos, e vice-versa, objetivando a transformação social e cumprindo-se o que se entende por função social da universidade.

Assim, o objetivo da extensão é criar uma relação entre a comunidade e a universidade, oportunizando vivências e desenvolvendo habilidades e ações que possibilitem uma troca de conhecimentos entre ambas. Por meio da extensão, a universidade leva à comunidade os saberes desenvolvidos em seus espaços. Nos dizeres de Machado (2013, p. 2),

Compreende-se que a relação universidade e sociedade é de suma relevância para ambas, na qual há uma produção de conhecimento crítico, reflexivo e comprometido com a realidade. Por isso, acredita-se que é fundamental discutir as finalidades e compromissos sociais da universidade, e que sua relação com a sociedade esteja concretizada como uma via de mão dupla, onde uma contribui com a outra. A Extensão Universitária é um espaço de integração da universidade com a sociedade, onde o conhecimento pode ser produzido na dialogicidade, independente do espaço, e que os saberes da comunidade devem ser valorizados e integrados aos conhecimentos científicos.

A extensão desenrola-se de maneira concreta através da pesquisa, de encontros, de atividades em campo, de ações culturais, sociais, assistenciais e assim por diante. Pode-se dizer que, nestas atividades, se beneficiam tanto a universidade quanto a comunidade, com a promoção do saber, por parte da comunidade para os estudantes; e a realização de projetos, por parte dos estudantes universitários para a comunidade. Para Machado (2013, p. 15), a visão que se tem da universidade, é que a mesma deve prestar serviço à comunidade, como uma via de mão única. Porém, ressalta que vem se desenvolvendo outra compreensão na qual a universidade troca conhecimento com a comunidade, como uma via de mão dupla.

Entendida a extensão e estabelecida sua relação entre o ensino e a pesquisa, passa-se a abordar o 
indissociável tripé ensino, pesquisa e extensão tratado na Lei 9.394/96 e na Resolução nº 5 de 2018.

\section{OS MECANISMOS UTILIZADOS PELAS UNIVERSIDADES NA FORMAÇÃO DO PROFISSIONAL JURISTA}

O curso superior de Direito é uma das graduações mais antigas e tradicionais do país, tendo as primeiras faculdades surgidas em 1827, em Olinda e São Paulo. Ocorre que, ainda hoje, os cursos de graduação em Direito atraem um considerável número de estudantes, que concorrem às vagas ofertadas em instituições públicas ou privadas, distribuídas em todo o território nacional.

Um questionamento válido, então, aparece: diante da ampla oferta de cursos de graduação em Direito espalhados pelo território brasileiro, gerando uma vasta quantidade de bacharéis, como as universidades devem atuar para formar profissionais juristas competentes, éticos e capazes de atuar nas demandas sociais?

Inspirada pela $\mathrm{CF} / 88$, a LDB traz, em seu artigo 52, que "as universidades são instituições pluridisciplinares de formação dos quadros profissionais de nível superior, de pesquisa, de extensão e de domínio e cultivo do saber humano". Conforme o artigo 43 da LDB, a educação superior tem por finalidade, dentre outras, "incentivar o trabalho de pesquisa e investigação científica, visando o desenvolvimento da ciência e da tecnologia e da criação e difusão da cultura, e, desse modo, desenvolver o entendimento do homem e do meio em que vive" (inciso III), "estimular o conhecimento dos problemas do mundo presente, em particular os nacionais e regionais, prestar serviços especializados à comunidade e estabelecer com esta uma relação de reciprocidade" (inciso VI) e "promover a extensão, aberta à participação da população, visando à difusão das conquistas e benefícios resultantes da criação cultural e da pesquisa científica e tecnológica geradas na instituição" (inciso VII).

Além disso, em consonância com o artigo 44 da referida legislação, a educação superior abrangerá, dentre outros, o projeto de extensão, aberto a candidatos que atendam aos requisitos estabelecidos em cada caso pelas instituições de ensino. A extensão é disposta também no artigo 53, o qual assegura as atribuições da universidade. Dentre essas, encontra-se a de "estabelecer planos, programas e projetos de pesquisa científica, produção artística e atividades de extensão" (art. 53, inciso III). Ademais, o $§ 2^{\circ}$ do artigo 77, assegura a possibilidade de apoio financeiro do poder público para a extensão, como é mencionado na Constituição Federal de 1988.

Por seu turno, a Resolução n ${ }^{\circ} 5$, traz, em seu $\S 2^{\circ}$, que os Projetos Pedagógicos (PPC) dos cursos de graduação em Direito devem abranger, “o incentivo, de modo discriminado, à pesquisa e à extensão, como fator necessário ao prolongamento da atividade de ensino e como instrumento para a iniciação científica". Além disso, traz que "as atividades de ensino dos cursos de Direito devem estar articuladas às atividades de extensão e de iniciação à pesquisa" $\left(\operatorname{art.} 2^{\circ}, \S 3^{\circ}\right)$.

Ademais, nos traz a referida Resolução, em seu artigo $4^{\circ}$, que os cursos de Direito devem utilizar de 
mecanismos que capacitem o graduando a demonstrar competência para a comunicação, leitura, compreensão e elaboração de textos, atos e documentos jurídicos, de caráter negocial, processual ou normativo, além da devida utilização das normas técnico-jurídicas; a dominar e aplicar conceitos, estruturas e racionalidades fundamentais ao exercício do Direito; a interpretar e aplicar as normas (princípios e regras) do sistema jurídico nacional, relacionando-as, quando preciso, com o sistema internacional; a otimizar técnicas de raciocínio e de argumentação, com objetivo de propor soluções e decidir questões no âmbito do Direito; a desenvolver a cultura do diálogo e o uso de meios consensuais de solução de conflitos; a compreender a hermenêutica e os métodos interpretativos, com a necessária capacidade de pesquisa e de utilização da legislação, da jurisprudência, da doutrina e de outras fontes do Direito; dentre outros $\left(\operatorname{art} .4^{\circ}\right)$.

Oberou-se, ainda, o enfoque à extensão no artigo $7^{\circ}$ da referida Resolução, o qual traz que os cursos de graduação em Direito devem estimular a realização de atividades curriculares de extensão, mediante vivências relativas ao campo de formação, de modo a oportunizar ações junto à comunidade.

Anterior à Resolução $n^{\circ} 5$ de 17 de dezembro de 2018, vigorava a Resolução $n^{\circ} 9$ de 29 de setembro de 2004 que, assim como aquela, instituía as diretrizes curriculares nacionais do curso de graduação em Direito. Nota-se, no entanto, um maior destaque em alguns pontos que a Resolução anterior não tratava, e que a nova passou a tratar. A mais recente trouxe, por exemplo, uma maior atenção para com as novas tecnologias da área jurídica, quando trata, no $\S 6^{\circ}$ do artigo $6^{\circ}$, do processo judicial eletrônico (PJE). Os procedimentos extrajudiciais também ganham bastante ênfase na nova Resolução, seja através do enfoque à seara extrajudicial ou pelo incentivo aos meios consensuais de resolução de conflitos (mediação, conciliação e arbitragem), os quais passaram a ser matéria obrigatória nos PPCs, o que não acontecia na antiga nota.

Além disso, em geral, percebe-se um maior cuidado no incentivo de estudantes mais próximos à realidade social, bem como nas atividades de pesquisa e extensão. Ambas já eram mencionadas na Resolução $\mathrm{n}^{\circ} 9$ de 2004, através do inciso VIII do artigo $2^{\circ}$, no entanto, passam a ser tratadas também em diversos artigos da nova nota. A título de exemplo, o artigo $9^{\circ}$ da atual Resolução traz a possibilidade das Instituições de Ensino Superior realizarem atividades extraclasse de inserções no âmbito geográfico e social, as quais possibilitam o desenvolvimento de conteúdos, competências e habilidades necessárias para a formação jurídica.

Assim, por meio da análise da LDB, bem como da Resolução $n^{\circ} 5$, é possível perceber o quanto se faz importante a presença assídua do ensino, da pesquisa e da extensão na vida acadêmica do estudante de Direito, seja à nível de graduação ou especialização. $\mathrm{O}$ indissociável tripé ensino, pesquisa e extensão constitui o suporte necessário para o desenvolvimento científico, tecnológico e cultural do país.

\section{CONSIDERAÇÕES FINAIS}

Ao final deste estudo, tornou-se possível compreender a importância de fazer presente o indissociável tripé ensino, pesquisa e extensão nas universidades e, em especial, nos cursos de graduação em 
Direito. Compreende-se que esses três pilares, quando aplicados em harmonia e presentes na formação acadêmica do estudante de Direito, refletem diretamente na sociedade.

É certo que uma relação estreita entre universidade e sociedade é de suma relevância para ambas. Deve o meio acadêmico ser um espaço no qual sociedade e universidade possam dialogar e pensar juntas, concretizando assim, uma produção social do conhecimento. Essa relação é solidificada por meio da extensão, associada à pesquisa e ao ensino. Os cursos de graduação em Direito devem, portanto, possibilitar que o aluno transforme a informação recebida na sala de aula em conhecimento prático, através das vivências proporcionadas pela extensão. Assim, faz-se necessário que a universidade, desfrutando-se de sua autonomia didático-científica e administrativa, desenvolva atividades que gerem novos campos de atuação com e participação da sociedade.

Conclui-se, pois, que a pesquisa e a extensão, associadas ao ensino, nos cursos de graduação em Direito compõem uma ferramenta de grande valor para a promoção do progresso, ao passo que, ao ultrapassarem os muros da universidade, não só complementam o que é estudado em sala de aula, como também oferecem ao corpo discente uma oportunidade de acompanhar de perto as demandas sociais.

\section{REFERÊNCIAS BIBLIOGRÁFICAS}

FREIRE, Paulo. Pedagogia da autonomia: saberes necessários à prática educativa, ed. 16. São Paulo: Ed Paz e Terra, 1996.

MACHADO, Verônica Moreno. Algumas reflexões sobre as concepções de extensão universitária. Revista Científica Semana Acadêmica. Fortaleza, ano MMXIII, nº. 000035,2013. Disponível em: http://abre.ai/aJM2. Acessado em: 05 fev. 2020.

WOLKMER, Antônio Carlos. História do Direito no Brasil, ed. 2. Rio de Janeiro: Forense, 2000. 